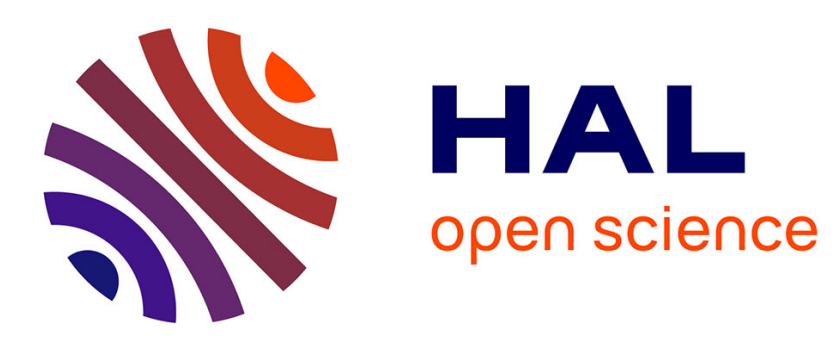

\title{
Towards new descriptors of basic nitrogen compounds in middle distillates by 2D NMR
}

\author{
D. Proriol, L. Chahen
}

\section{To cite this version:}

D. Proriol, L. Chahen. Towards new descriptors of basic nitrogen compounds in middle distillates by 2D NMR. Energy \& Fuels, 2020, 34 (2), pp.1347-1354. 10.1021/acs.energyfuels.9b03199 . hal02553541

\section{HAL Id: hal-02553541 \\ https://hal-ifp.archives-ouvertes.fr/hal-02553541}

Submitted on 24 Apr 2020

HAL is a multi-disciplinary open access archive for the deposit and dissemination of scientific research documents, whether they are published or not. The documents may come from teaching and research institutions in France or abroad, or from public or private research centers.
L'archive ouverte pluridisciplinaire $\mathbf{H A L}$, est destinée au dépôt et à la diffusion de documents scientifiques de niveau recherche, publiés ou non, émanant des établissements d'enseignement et de recherche français ou étrangers, des laboratoires publics ou privés. 


\title{
Towards new descriptors of basic nitrogen
}

\section{compounds in middle distillates by 2D NMR}

\author{
D. Proriol*, L. Chahen,
}

IFP Energies nouvelles, Rond-point de l'échangeur de Solaize, BP 3, 69360 Solaize, France

KEYWORDS: Basic Nitrogen, Middle distillates, NMR, HSQC, NMR Prediction, isoquinoline

ABSTRACT: Basic nitrogen-compounds (N-compounds), present in middle distillates, can inhibit acidic catalysts used in hydrotreatment processes. A better knowledge of these compounds, especially the environment of the nitrogen atom, may be interesting to improve these processes. Herein, we propose a new promising methodology coupling the extraction of the basic N-compounds by flash chromatography with 2D NMR analysis. The NMR sequence Heteronuclear Single-Quantum Correlation (HSQC) allows to visualize specific C-H correlations and, with the help of the prediction software Advanced Chemistry Development/Laboratory (PSACDL), eleven areas of interest have been identified. The representativeness of these areas have been validated with data from literature and with a gas oil (GO) sample analysis. These areas are specific to $\mathrm{C}-\mathrm{H}$ couples in pyridine, quinoline, isoquinoline and acridine derivatives and give a detailed fingerprint of basic N-compounds in the GO cut. Moreover, certain areas allow to describe the close environment of the nitrogen atom and allow, for example, to differentiate isoquinoline from quinoline derivatives. 


\section{INTRODUCTION}

Organic nitrogen compounds (N-compounds) in middle distillates are known for inhibiting the process of the hydrodesulfurization (HDS $)^{1-4}$. In the literature, these compounds are classically divided into two distinct groups: "neutral compounds" (derivatives of pyrrole) and "basic compounds" (derivatives of pyridine). This work is focused on basic N-compounds which are suspected to be potential inhibitors of acid catalysts. The basic N-compounds include pyridine, quinoline, acridine, benzoquinoline and their alkylated analogs $s^{5,6}$. Besides pyridine, quinoline or acridine are often used as model molecules to investigate the influence of the $\mathrm{N}$-compounds on the catalytic activity for $\operatorname{HDS}^{7,8}$.

Nowadays, two-dimensional gas chromatography $(\mathrm{GC} \times \mathrm{GC})$ is the most developped technique $^{4,9}$ to characterize N-compounds in complex matrices, such as fossil fuels, especially when it is coupled with specific detectors like nitrogen chemiluminescence detector $(\mathrm{NCD})^{3,10,14,15}$, nitrogen-phosphorus detector, atomic emission detector ${ }^{11}$ or mass spectrometry $(\mathrm{MS})^{12,13}$.

Although the high peak capacity of $\mathrm{GC} \times \mathrm{GC}$, coelutions remain present, mainly between quinolines and anilines, indoles and quinolines or carbazoles and acridines. In order to narrow these coelutions, N-compounds are generally extracted from hydrocarbons by solid phase extraction (SPE) to give 2 isolated fractions: basic and neutral fractions ${ }^{16,17}$. By coupling SPE and $\mathrm{GC} \times \mathrm{GC}$, it is possible to access the accurate quantification of $\mathrm{N}$-compounds by families like pyridines, quinolines or acridines. However, $\mathrm{GC} \times \mathrm{GC}$ does not allow to access information on the environment of the nitrogen atom. For example, 2,6-dimethylquinoline and 3,5dimethylquinoline are quantified as quinolines by GCxGC-NCD even if the steric influence of the methyl group on positions 2 and 6 may change the reactivity of the nitrogen atom on an 
acidic site of a catalyst. Similarly, GCxGC is not able to make the difference between an isoquinoline and a quinoline which have very similar structures but different basicities. Consequently, knowing the environment of the nitrogen atom could be just as important as quantifying the different families to describe the inhibitor character of a middle distillate.

In our previous work, we proposed an approach coupling SPE, derivatization with $\mathrm{BF}_{3}$ of non protogenic nitrogen species and the use of NMR analysis ${ }^{18}$. By crossing information from ${ }^{19} \mathrm{~F}$, ${ }^{1} \mathrm{H},{ }^{1} \mathrm{H}-{ }^{19} \mathrm{~F}$ HMBC and ${ }^{19} \mathrm{~F}$ DOSY, it is possible to determine the close environment of the nitrogen atom of the most nucleophilic nitrogen compounds in GO. However, the intermediate step of derivatization with $\mathrm{BF}_{3}$ makes complex the procedure and its extension from a qualitative to a quantitative method.

During the previous work, we noticed that pyridine derivatives, extracted from a GO, showed specific chemical shifts in ${ }^{1} \mathrm{H}$ or in ${ }^{13} \mathrm{C}$ compared to their hydrocarbon analogues. In 1D NMR, these specificities are not enough to give accurate information about the structures of $\mathrm{N}$ compounds. However, 2D NMR, coupling ${ }^{1} \mathrm{H}$ and ${ }^{13} \mathrm{C}$, should increase the singularities of each C-H couples, facilitate their differentiation and their identification. Thus, the aim of this work is to demonstrate the possibility to access new information about the structure of the basic Ncompounds and the environment of the nitrogen atom without derivatization prior to analysis by 2D NMR.

In the first part of this study, 2D NMR spectra of almost 150 basic aromatic N-compounds were simulated with Advanced Chemistry Development/Laboratory software ${ }^{19}$ (PS-ACDL). The resulting 2D NMR cartography of proton/carbon correlations shows isolated and specific areas which validate the main theory. In the latter part, different sequences were tested and adjusted to 
the specificities of a real sample extracted from a coker GO. The theoretical and experimental cartographies were compared in order to validate the full approach.

\section{EXPERIMENTAL SECTION}

Chemicals. All nitrogen compounds were purchased from Sigma-aldrich and were used without further purification. Dichloromethane- $d_{2}\left(\mathrm{CD}_{2} \mathrm{Cl}_{2}\right)$ and chloroform- $d\left(\mathrm{CDCl}_{3}\right)$ were purchased from Euriso-top and dried on activated molecular sieves ( $3 \AA$ ). The silica used for the extraction was Merck silica (40-63 $\mu \mathrm{m}, 0.8 \mathrm{~cm}^{3} / \mathrm{g}$ pore volume, $480-540 \mathrm{~m}^{2} / \mathrm{g}$ ). Silica is kept at $110{ }^{\circ} \mathrm{C}$ for at least $24 \mathrm{~h}$ before use. The gas oil (GO) was obtained from a coker unit and it contains about 1200 wppm of nitrogen and 550 wppm of basic N-compounds. The coker GO was not hydrotreated.

Extraction Protocol on GO. Basic N-compounds were extracted by flash chromatography which was adapted from Chahen et al. ${ }^{18}$. PLC 2250 (Gilson) with silica column (40 g, Ø $\left.30 \mathrm{~mm}\right)$ equipped with a UV detector was used for flash chromatography separation. The flow rate was kept at $40 \mathrm{~mL} / \mathrm{min}$ for different solvents. Before use, the cartridge was conditioned with $200 \mathrm{~mL}$ of heptane, then $28,1 \mathrm{~mL}$ of sample was injected into the silica column. The hydrocarbon matrix was eluted from the column with $480 \mathrm{~mL}$ of n-heptane whereas $\mathrm{N}$-compounds were trapped on the silica column. Neutral N-compounds and anilines were eluted off the column with $400 \mathrm{~mL}$ of dichloromethane while basic $\mathrm{N}$-compounds were eluted with $240 \mathrm{~mL}$ of acetone. The acetone fraction was dried on $\mathrm{MgSO}_{4}$ and filtered, and acetone was evaporated slowly in a rotary evaporator to give $200 \mathrm{mg}$ of oily mixture.

NMR Experiments. Samples for NMR were prepared using $200 \mathrm{mg}$ of basic N-compounds from the GO dissolved in $300 \mu \mathrm{L}$ of the $\mathrm{CD}_{2} \mathrm{Cl}_{2}$ or $\mathrm{CDCl}_{3} .{ }^{1} \mathrm{H} \mathrm{NMR}(300.13 \mathrm{MHz})$ and ${ }^{13} \mathrm{C} \mathrm{NMR}$ 
(75.47 MHz) spectra were recorded on a Bruker Avance III NMR spectrometer with a BroadBand probe (BBFO) using $5 \mathrm{~mm}$ o.d. glass NMR tubes. The chemical shifts are reported in $\delta(\mathrm{ppm})$ values. ${ }^{1} \mathrm{H}$ NMR chemical shifts were referenced to the residual solvent peak: 5.32 or $7.26 \mathrm{ppm}$ for proton resonance of dichloromethane or chloroform, respectively. ${ }^{13} \mathrm{C}$ NMR chemical shifts were referenced to the residual solvent peak: 53.84 or $77.16 \mathrm{ppm}$ for carbon resonance of dichloromethane or chloroform, respectively. The pulse program "hjresqf" was used to measure coupling constants and different pulse programs "hsqc" from Bruker's library were tested to record Heteronuclear Single-Quantum Correlation (HSQC).

The 2D proton J-resolved spectroscopy experiments were acquired with for $64 \times 512$ points spectral widths of $400 \mathrm{~Hz} \times 4500 \mathrm{~Hz}(\mathrm{~F} 1 \times \mathrm{F} 2)$, a $9 \mu \mathrm{s} \pi / 2 \mathrm{RF}$ pulse length, a $2 \mathrm{~s}$ pulse repetition time, 16 scans, and a total acquisition time of $38 \mathrm{~min}$. The number of scans was adjusted according to the samples. For ${ }^{1} \mathrm{H}^{-13} \mathrm{C} 2 \mathrm{D}$ HSQC, spectral widths were approximately $1.2 \mathrm{kHz}$ for ${ }^{1} \mathrm{H}$ dimension between 6 and $10 \mathrm{ppm}$ and $6 \mathrm{kHz}$ for ${ }^{13} \mathrm{C}$ between 95 and $175 \mathrm{ppm}$. Sensitivityenhanced ${ }^{1} \mathrm{H}_{-}{ }^{13} \mathrm{C} 2 \mathrm{D}$ HSQC experiments were performed employing an INEPT transfer delay of $1,47 \mathrm{~ms}$ corresponding to a ${ }^{1} J_{\mathrm{C}-\mathrm{H}}$ of $170 \mathrm{~Hz}$. 256 free induction decays were collected along the indirect (t1) dimensions using 32 scans per increment and a $4 \mathrm{~s}$ recycle delay, resulting in a total acquisition time of about $10 \mathrm{~h}$ for the ${ }^{1} \mathrm{H}_{-}{ }^{13} \mathrm{C}$ HSQC. Phase sensitive data were obtained using echo-antiecho mode with carbon (for ${ }^{1} \mathrm{H}^{13} \mathrm{C}$ HSQC) decoupling during acquisition (t2 dimension) using the GARP sequence.

Software and data base. The prediction software of the Advanced Chemistry Development/Laboratory ${ }^{19}$ (PS-ACDL) is mainly based on experimental data. When a molecule is in its database, the software gives the experimental spectra. When a molecule is not in its database, the software uses algorithms and experimental spectra from the closest molecules from 
its database to predict a spectrum. PS-ACDL can predict ${ }^{1} \mathrm{H}$ and ${ }^{13} \mathrm{C}$ spectra in divers solvents since its algorithms consider also solvent effects. However, the version of PS-ACDL used in this work do not predict 2D NMR spectra. The correlations between ${ }^{1} \mathrm{H}$ and ${ }^{13} \mathrm{C}$ were done manually for each compound.

Spectral Database for Organic Compounds ${ }^{20}$ (B-SDBS) is, inter alia, a database of NMR's spectra. This base was built from experimental spectra recorded usually in $\mathrm{CDCl}_{3}$ and was used to compare with PS-ACDL.

\section{RESULTS AND DISCUSSION}

\section{Model molecules}

In the literature, basic aromatic N-compounds in acetone extract are separated in three families: pyridine, quinoline and acridine derivatives. Although suspected, isoquinolines are never considered since it is almost impossible to separate them from quinolines by $\mathrm{GC} \times \mathrm{GC}$ and to be clearly identified by mass spectrometry. 150 model molecules were considered with 15 pyridine, 47 quinoline, 45 isoquinoline and 43 acridine derivatives. The derivatives differ mainly from the head of the family by alkyl substitutions at different positions. According to literature, both the $\delta_{\mathrm{H}}$ and the $\delta_{\mathrm{C}}$ are weakly impacted by the nature of alkyl substituent (methyl, ethyl, isopropyl, etc... $)^{21-23}$. Consequently, only methyl alkylations at different positions were considered. The full list of basic aromatic N-compounds simulated is reported in supplementary information (Table S1).

For each model molecule, both ${ }^{1} \mathrm{H}$ chemical shift $\left(\delta_{\mathrm{H}}\right)$ and ${ }^{13} \mathrm{C}$ chemical shift $\left(\delta_{\mathrm{C}}\right)$ of the aromatic cycle containing the nitrogen atom were determined by PS-ACDL. Each C-H correlation of a head of family is represented by a geometric form with a dark blue outline to 
help visualization. PS-ACDL correlations were predicted in $\mathrm{CDCl}_{3}$ since the database is the most complete.

The nomenclature of the different families is called to mind in the Table 1. This nomenclature respects the IUPAC nomenclature for pyridine, quinoline, isoquinoline and acridine derivatives. However, it was adapted for "Benzo derivatives" in order to keep the same position in relative to the nitrogen atom.

Table 1: Nomenclature of the different families 


\section{$\underline{\text { Pvridine Familv }}$}<smiles>c1ccncc1</smiles>

Pyridine

\section{Quinoline Familv}<smiles>c1ccc2ncccc2c1</smiles>

Quinoline<smiles>c1ccc2c(c1)ccc1cccnc12</smiles>

Benzo(h)quinoline<smiles>c1ccc2c(c1)ccc1ncccc12</smiles>

Benzo(f)quinoline

\section{Isoquinoline Familv}<smiles>c1ccc2cnccc2c1</smiles><smiles>c1ccc2c(c1)ccc1ccncc12</smiles>

Isoquinoline<smiles>c1ccc2c(c1)ccc1cnccc12</smiles>

Benzo(f)isoquinoline

\section{$\underline{\text { Acridine Familv }}$}<smiles>c1ccc2nc3ccccc3cc2c1</smiles>

Acridine<smiles>c1ccc2nc3c(ccc4ccccc43)cc2c1</smiles>

Benzo(c)acridine<smiles>c1ccc2nc3ccc4ccccc4c3cc2c1</smiles>

Benzo(a)acridine

\section{Comparison between PS-ACDL and B-SDBS}


Pyridine derivatives are the simplest molecules of basic aromatic N-compounds with one single aromatic ring. B-SDBS contains the NMR spectra of 11 pyridine derivatives on the 15 simulated by PS-ACDL . So pyridine derivatives are ideal to compare the prediction of PSACDL with B-SDBS (Figure 1). The signals of pyridine (head of family) are easily located with a dark blue outline.

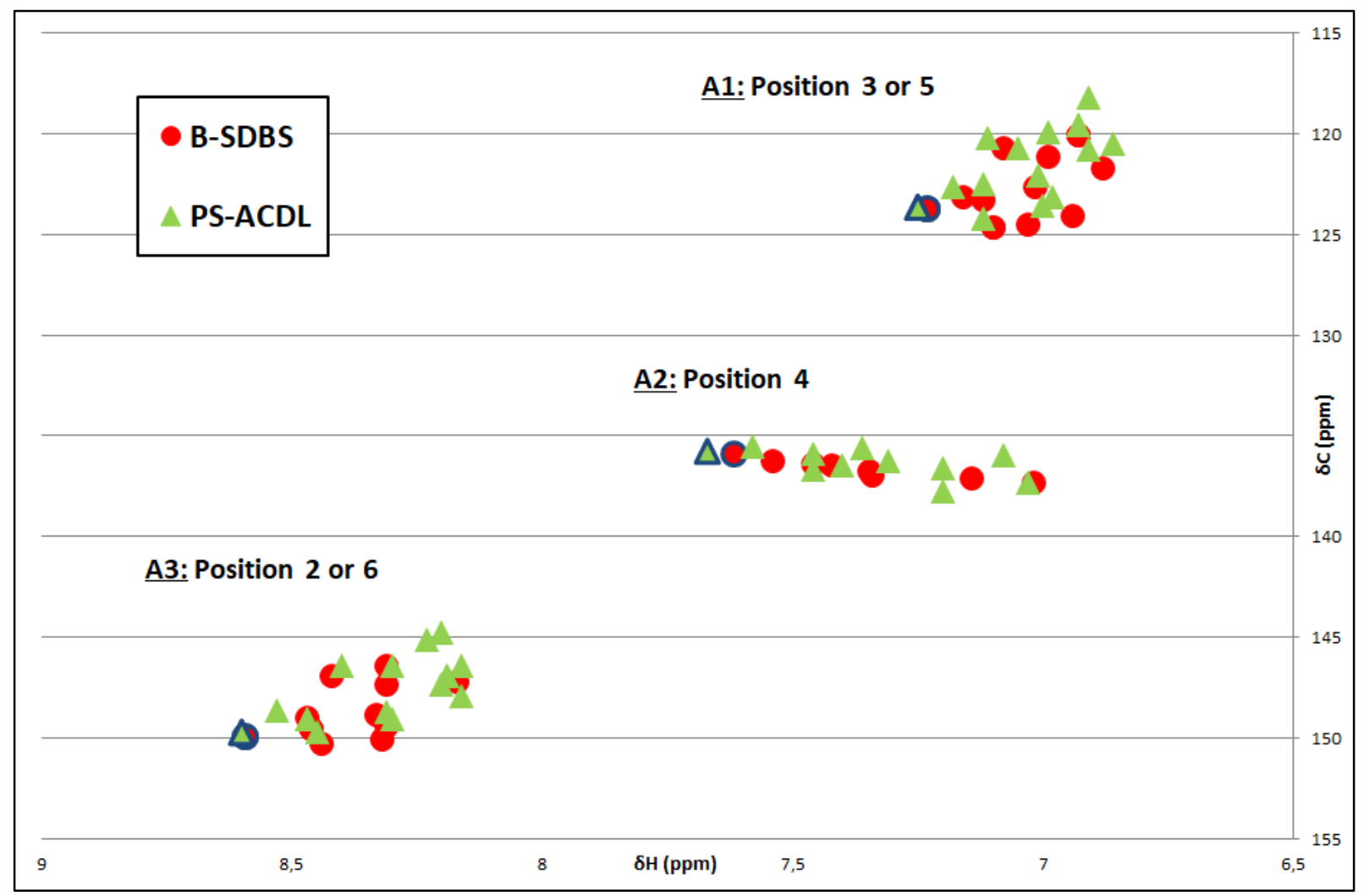

Figure 1. $\left\{{ }^{1} \mathrm{H},{ }^{13} \mathrm{C}\right\}$ HSQC spectra of pyridine derivatives simulated by PS-ACDL and given by B-SDBS.

With both prediction software and database, three distinct areas stand out according to the position of the $\mathrm{C}-\mathrm{H}$ correlation relative to the nitrogen atom. In this study, the correlation of carbon in position $\mathrm{n}$ with proton in position $\mathrm{n}$ is noted $\mathrm{C}^{\mathrm{n}}-\mathrm{H}^{\mathrm{n}}$. To facilitate understanding, each area is numbered with a letter $\mathrm{A}$ following by a number. $\mathrm{C}^{3}-\mathrm{H}^{3}$ and $\mathrm{C}^{5}-\mathrm{H}^{5}$ correlations of 
pyridine derivatives are gathered in $\mathrm{A} 1$, while $\mathrm{C}^{4}-\mathrm{H}^{4}$ correlations are regrouped in $\mathrm{A} 2 . \mathrm{A} 3$ contains $\mathrm{C}^{2}-\mathrm{H}^{2}$ and $\mathrm{C}^{6}-\mathrm{H}^{6}$ correlations.

The dispersion of predicted correlations with PS-ACDL is very close to whose given by BSDBS. In all cases, protons of pyridine in each area are always the most deshielded in ${ }^{1} \mathrm{H}$ NMR. This observation is confirmed by the literature with pyridine and alkylated pyridine derivatives ${ }^{24}$. Finally, the predicted correlations made with PS-ACDL seem accurate and PS-ACDL can be used to predict quinoline, isoquinoline and acridine derivatives with confidence.

\section{Prediction of C-H correlations}

47 quinoline derivatives were considered. 34 have a proton in position 2, 35 have a proton in position 3 and 34 have a proton in position 4 . The full cartography of this family predicted with PS-ACDL is given in Figure S1 in supplementary materials. This cartography is complex because of the presence of aromatic signals due to hydrocarbon aromatic cycle in quinoline structure. To facilitate the comprehension, these signals are removed in Figure 2 which allows to notice three new distinct areas: A4, A5 and A6.

$\mathrm{C}^{3}-\mathrm{H}^{3}$ correlations of quinoline derivatives are observed at $\delta_{\mathrm{H}} / \delta_{\mathrm{C}}$ of 7-7.5/119-124 ppm and are gathered in A4. 32 out of the 35 quinoline derivatives simulated have their protons in position 3 located in this area. Only benzo(f)quinoline (represented by grey cross) with a correlation at $\delta_{\mathrm{H}} / \delta_{\mathrm{C}}$ of $7.45 / 116.7 \mathrm{ppm}$ and bisquinoline family have their $\mathrm{C}^{3}-\mathrm{H}^{3}$ signals outside this area. However, Jiang et al. ${ }^{25}$ synthesized and analyzed benzo(f)quinoline. They indicated the $\mathrm{C}^{3}-\mathrm{H}^{3}$ correlation at $\delta_{\mathrm{H}} / \delta_{\mathrm{C}}$ of $7.56 / 121.3 \mathrm{ppm}$ which confirms that PS-ACDL has difficulty to predict $\mathrm{C}^{3}-\mathrm{H}^{3}$ correlations of benzo(f)quinoline. As a result, all $\mathrm{C}^{3}-\mathrm{H}^{3}$ correlations of quinoline and benzoquinoline derivatives are in the same zone A4. Few signals are more deshielded than 
quinoline in ${ }^{1} \mathrm{H}$ NMR, but these belong to benzoquinolines or 8-hydroxyquinoline, two very specific species.

The area, corresponding to $\mathrm{C}^{4}-\mathrm{H}^{4}$ correlations of quinoline derivatives, is divided into two distinct parts: A5 and A5'.

- A5 extends from 7.8 to $8.3 \mathrm{ppm}$ in ${ }^{1} \mathrm{H}$ and from 130 to $140 \mathrm{ppm}$ in ${ }^{13} \mathrm{C}$. A5 is located just below hydrocarbon aromatic protons signals. It groups 29 simulated quinoline derivatives.

- A5' has similar chemical shifts in ${ }^{13} \mathrm{C}$ but is most deshielded in ${ }^{1} \mathrm{H}$ (8.5-9.2 ppm). This area groups all $\mathrm{C}^{4}-\mathrm{H}^{4}$ correlations predicted for specific benzo(f)quinoline derivatives.

A5" (zone colored in yellow in Figure 2) is a part of A5. This area corresponds to $\mathrm{C}^{4}-\mathrm{H}^{4}$ correlations of quinoline derivatives alkylated in position 5. The lower chemical shifts $\delta_{\mathrm{C}}{ }^{4}$ of A5", are validated in the literature where $\delta_{\mathrm{C}}{ }^{4}$ for 5,8 -dimethylquinoline ${ }^{26}, 5,7-$ dimethylquinoline $^{27}$ and 5-methylquinoline ${ }^{28}$ are measured at 131.9, 132.4 and $132.7 \mathrm{ppm}$, respectively. In A5", few signals are more deshielded in ${ }^{1} \mathrm{H}$ than quinoline. The literature confirms also these data, by reporting for 5-methylquinoline ${ }^{28}$ and 5,7-dimethylquinoline ${ }^{27}$, chemical shifts $\delta_{\mathrm{H}}{ }^{4}$ of 8.31 and $8.26 \mathrm{ppm}$, respectively.

$\mathrm{C}^{2}-\mathrm{H}^{2}$ correlations of quinoline derivatives were observed at $\delta_{\mathrm{H}} / \delta_{\mathrm{C}}$ of $8.6-9.0 / 147-152 \mathrm{ppm}$ and are gathered in A6. According to PS-ACDL, 32 of the 34 predicted $\mathrm{C}^{2}-\mathrm{H}^{2}$ correlations are in this zone. The two molecules outside A6 correspond to phenanthridine and 3,4-dimethylquinoline.

The $\mathrm{C}^{2}-\mathrm{H}^{2}$ correlation of phenanthridine was observed at $\delta_{\mathrm{H}} / \delta_{\mathrm{C}}$ of $9.31 / 153.76 \mathrm{ppm}$. B-SDBS confirms this correlation at $\delta_{\mathrm{H}} / \delta_{\mathrm{C}}$ of $9.26 / 153.5 \mathrm{ppm}$. This specific $\mathrm{C}^{2}-\mathrm{H}^{2}$ correlation is certainly due to the fact that phenanthridine can also be considered as an isoquinoline derivative. 
Therefore, this correlation may be considered as a $\mathrm{C}^{1}-\mathrm{H}^{1}$ correlation of isoquinoline rather than a $\mathrm{C}^{2}-\mathrm{H}^{2}$ correlation of quinoline.

The $\mathrm{C}^{2}-\mathrm{H}^{2}$ correlation of 3,4-dimethylquinoline was observed at $\delta_{\mathrm{H}} / \delta_{\mathrm{C}}$ of $8.42 / 152.2 \mathrm{ppm}$. However, Yan et al. ${ }^{29}$ synthesized this molecule and measured the $\mathrm{C}^{2}-\mathrm{H}^{2}$ correlation at $\delta_{\mathrm{H}} / \delta_{\mathrm{C}}$ of 8.68/152.48 ppm which is finally located in A6.

PS-ACDL predicts a $\delta_{\mathrm{H}}$ of $9.04 \mathrm{ppm}$ for 5-methylquinoline which is higher than the $\delta_{\mathrm{H}}$ of quinoline $(8.91 \mathrm{ppm})$. Rousseaux et al. ${ }^{28}$ synthesized this molecule and measured a $\delta_{\mathrm{H}}$ of 8.90 ppm. This result confirms that PS-ACDL slightly tends to overestimate $\delta_{\mathrm{H}}$ for quinoline derivatives and that quinoline can be considered as head of family.

According to PS-ACDL, even if benzenic correlations are closed to A4 and A5, they do not interfere with these areas. There is only one exception, at $\delta_{H} / \delta_{C}$ of $8.08 / 131.84 \mathrm{ppm}$ (clear grey square in Figure S1). This exception corresponds to the correlation of 4,4'-dimethyl-2,2'biquinoline. For this molecule, B-SDBS reports a correlation at $\delta_{\mathrm{H}} / \delta_{\mathrm{C}}$ of $8.23 / 130.56 \mathrm{ppm}$ which was confirmed by Larionov et $a .^{30}$. So the correlation of this molecule was located outside A5". 


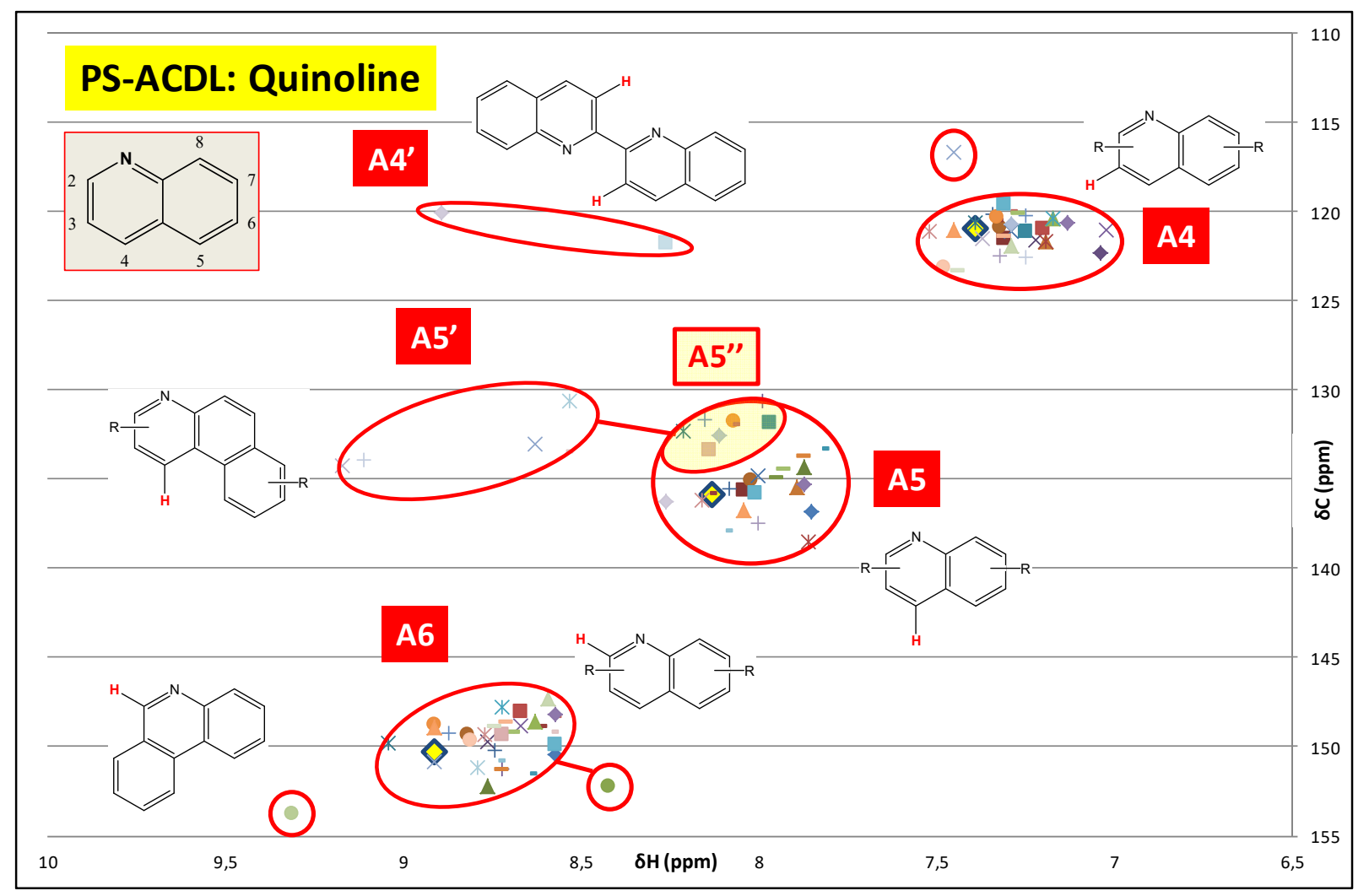

Figure 2. $\{1 \mathrm{H}, 13 \mathrm{C}\}$ HSQC spectrum of quinoline derivatives simulated by PS-ACDL without benzenic correlations.

Following the same approach as with quinoline derivatives, it is possible to establish different areas specific to pyridine, isoquinoline and acridine derivatives (Figure S2 to Figure S6 in supporting materials).

After correcting aberrant correlations by comparing with the literature and after controlling that each area did not interfere with benzenic correlations, all areas were gathered in the same graphic (Figure 3). Blue areas from A1 to A3 correspond to the three different $\mathrm{C}-\mathrm{H}$ correlations of pyridine derivatives. Red areas from A4 to A6 correspond to the three different $\mathrm{C}-\mathrm{H}$ correlations of quinoline derivatives. Green areas from A7 to A9 refer to the three different $\mathrm{C}-\mathrm{H}$ 
correlations of isoquinoline derivatives and, finaly, purple area $\mathrm{A} 10$ contains $\mathrm{C}^{9}-\mathrm{H}^{9}$ correlations of acridines derivatives.

$\mathrm{C}^{1}-\mathrm{H}^{1}$ correlations of isoquinoline derivatives are located in three areas. The major part, 22 of 34 predicted correlations, is in A9. A9' contains isoquinoline derivatives substituted in position 8 which includes also benzo(h)isoquinolines derivatives. However, the very specific benzo(h)isoquinoline derivatives substituted in position 3 are located in A9".

$\mathrm{C}^{9}-\mathrm{H}^{9}$ correlations of acridine derivatives are divided in two parts. A10' regroups correlations of acridine derivatives substituted in position 1 or/and 8 while $\mathrm{A} 10$ clusters all other $\mathrm{C}^{9}-\mathrm{H}^{9}$ correlations of acridine derivatives. Unfortunately, A10' and A5' are fully superposed and, consequently, it is not possible to separate the signals of $\mathrm{C}^{4}-\mathrm{H}^{4}$ correlations predicted for benzo(f)quinoline derivatives and the signals of $\mathrm{C}^{9}-\mathrm{H}^{9}$ correlations of acridine derivatives substituted in position 1 or/and 8.

There is also an important overlay between $\mathrm{A} 1$ and $\mathrm{A} 4$ which gather $\mathrm{C}^{3}-\mathrm{H}^{3}$ correlations of pyridine and quinoline derivatives. Other overlays can be considered as minor and have to be checked in details since the areas are delimited with regular ellipses and could be delimited more finely with non geometric forms.

Even if it is not possible to discriminate every correlation, it is interesting to distinguish at least correlations close to nitrogen atom (position ortho) of pyridine $\left(\mathrm{C}^{2}-\mathrm{H}^{2}\right.$ in $\mathrm{A} 3$ ), quinoline $\left(\mathrm{C}^{2}-\mathrm{H}^{2}\right.$ in A6) and isoquinoline $\left(\mathrm{C}^{1}-\mathrm{H}^{1}\right.$ in $\mathrm{A} 9, \mathrm{C}^{3}-\mathrm{H}^{3}$ in $\left.\mathrm{A} 8\right)$ derivatives. A signal in these areas means that the corresponding nitrogen compound has at least an hydrogen atom in ortho position. Consequently, this ortho position is not sterically hindered and the nucleophilicity of the nitrogen atom is certainly higher than in hindered compounds. This compounds may certainly react faster and stronger with the acidic sites of a catalyst. Thus, the cartography may be a new tool or a new 
way to understand, to describe and to predict the inhibitor character of middle distillates in hydrotreatment for example.

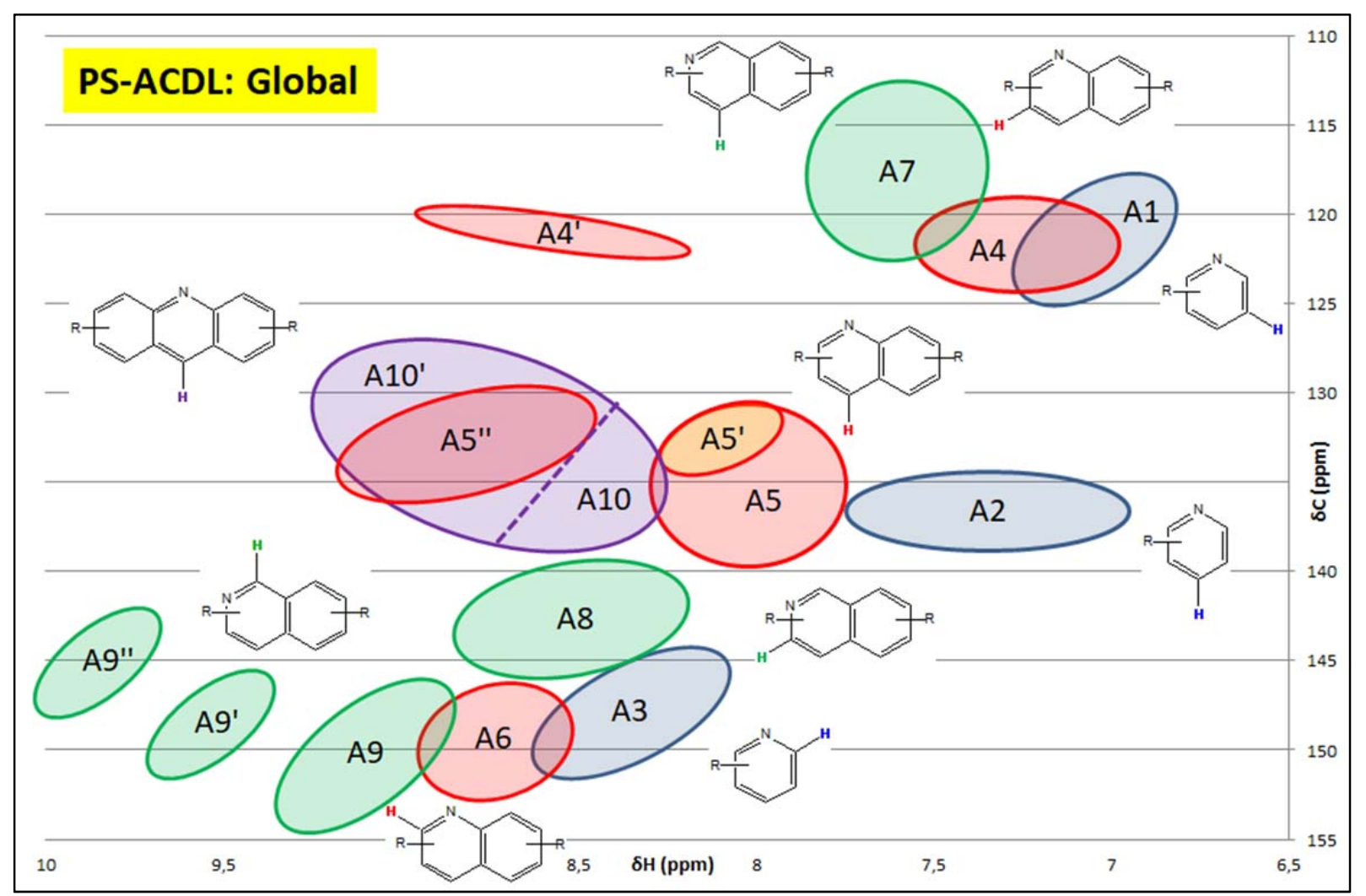

Figure 3. Prediction by PS-ACDL of C-H correlation in 2D NMR of pyridine (blue), quinoline (red), isoquinoline (green) and acridine (purple) derivatives.

The predicted cartography was realized in $\mathrm{CDCl}_{3}$ because, in the literature as in PS-ACDL database, most of spectra of pyridine, quinoline or acridine derivatives were acquired in this solvent. Consequently, the software gives more reliable predictions in $\mathrm{CDCl}_{3}$. However, using $\mathrm{CDCl}_{3}$ as solvent presents disadvantages : i) $\mathrm{CDCl}_{3}$ contents residual acids which can react with the basic nitrogen compounds to form pyridinium derivatives and generate chemical shifts. ii) The differences observed between the chemical shifts of a nitrogen compound alone and in mixture in $\mathrm{CDCl}_{3}$ are generally significant in comparison to whose observed for $\mathrm{CD}_{2} \mathrm{Cl}_{2}$ as 
example. iii) The residual solvent peak of the $\mathrm{CDCl}_{3}$ in ${ }^{1} \mathrm{H}$ NMR is in the range of interest and may cause consequent artifacts by folding effect in 2D NMR with restricted spectral widths. Consequently, experimental 2D NMR spectra were done in $\mathrm{CD}_{2} \mathrm{Cl}_{2}$ keeping in mind that areas may be slightly shifted compare to predictions in $\mathrm{CDCl}_{3}$, especially in ${ }^{1} \mathrm{H}$ dimension since proton shifts are generally more sensitive to solvent change that carbon shifts.

\section{D NMR Spectroscopy of GO}

Heteronuclear Single Quantum Coherence Spectroscopy (HSQC) and Heteronuclear MultipleQuantum Correlation (HMQC) are used to correlate the chemical shift of ${ }^{1} \mathrm{H}$ (displayed on the F2 axis) to the ${ }^{13} \mathrm{C}$ chemical shift (on the "indirect," $\mathrm{F} 1$ axis) of their directly attached carbon. HMQC spectra may have better signal to the noise ratio $(\mathrm{S} / \mathrm{N})$ than HSQC spectra because HMQC pulse sequence is significantly shorter ${ }^{31}$. However, HSQC spectra feature generally better line shapes than HMQC and the commonly used multiplicity-edited HSQC versions offer the added benefit of distinguishing $\mathrm{CH}_{3}, \mathrm{CH}_{2}$, and $\mathrm{CH}$ groups. Moreover, it is possible to use adiabatic ${ }^{13} \mathrm{C}$-pulses in the HSQC sequence which can significantly improve the sensitivity of the signal and allows to make quantitative 2D NMR spectra ${ }^{32,33}$. So, the HSQC is very often used for direct C-H correlations.

In HSQC pulse sequences, the total delay in the spin echo is important and depends on the magnitude of the one-bond carbon-proton coupling constant $\left({ }^{1} \mathrm{~J}_{\mathrm{CH}}\right)$. This delay time is routinely set according to an average ${ }^{1} \mathrm{~J}_{\mathrm{CH}}$ value of $145 \mathrm{~Hz}$. However, in order to optimize the sequence, ${ }^{1} \mathbf{J}_{\mathrm{CH}}$ of few model basic nitrogen compounds were measured and summarized in Table 2. Their coupling constants vary between 160 to $180 \mathrm{~Hz}$. Consequently, a delay time of $170 \mathrm{~Hz}$ was chosen as average value. Several sequences were tested from the Bruker's library. The sequence "hsqcetgpsi" ${ }^{34}$ offers the best outcome. In this sequence, the lock is restored before the 
acquisition. In certain cases, restoring the lock after the acquisition tends to improve the quality of the signal. Consequently, all experiments were recorded this way.

Table 2: Coupling constants ${ }^{1} \mathrm{~J}_{\mathrm{CH}}$ of different family in $\mathrm{Hz}$

\begin{tabular}{|c|c|c|c|c|}
\hline Position & Pyridine & Quinoline & Isoquinoline & Acridine \\
\hline 1 & - & - & 180,3 & 160,6 \\
\hline 2 & 181,1 & 177,8 & - & 159,8 \\
\hline 3 & 160,7 & 164,3 & 178,1 & 161,7 \\
\hline 4 & 162,7 & 158,6 & 163,2 & 158,7 \\
\hline 9 & - & - & - & 159,1 \\
\hline
\end{tabular}

To decrease the time of acquisition, the signal was recorded only from 6 to $10 \mathrm{ppm}$ in ${ }^{1} \mathrm{H}$ and from 95 to $175 \mathrm{ppm}$ in ${ }^{13} \mathrm{C}$. This carbon spectral width was adjusted to avoid folding effects of alkyl signals on the areas of interest. GO was submitted to the extraction protocol described in Experimental Section and the basic nitrogen fraction was submitted to HSQC analysis. The HSQC spectrum of the GO is reported in Figure 4 with the areas of interest from Figure 3. 


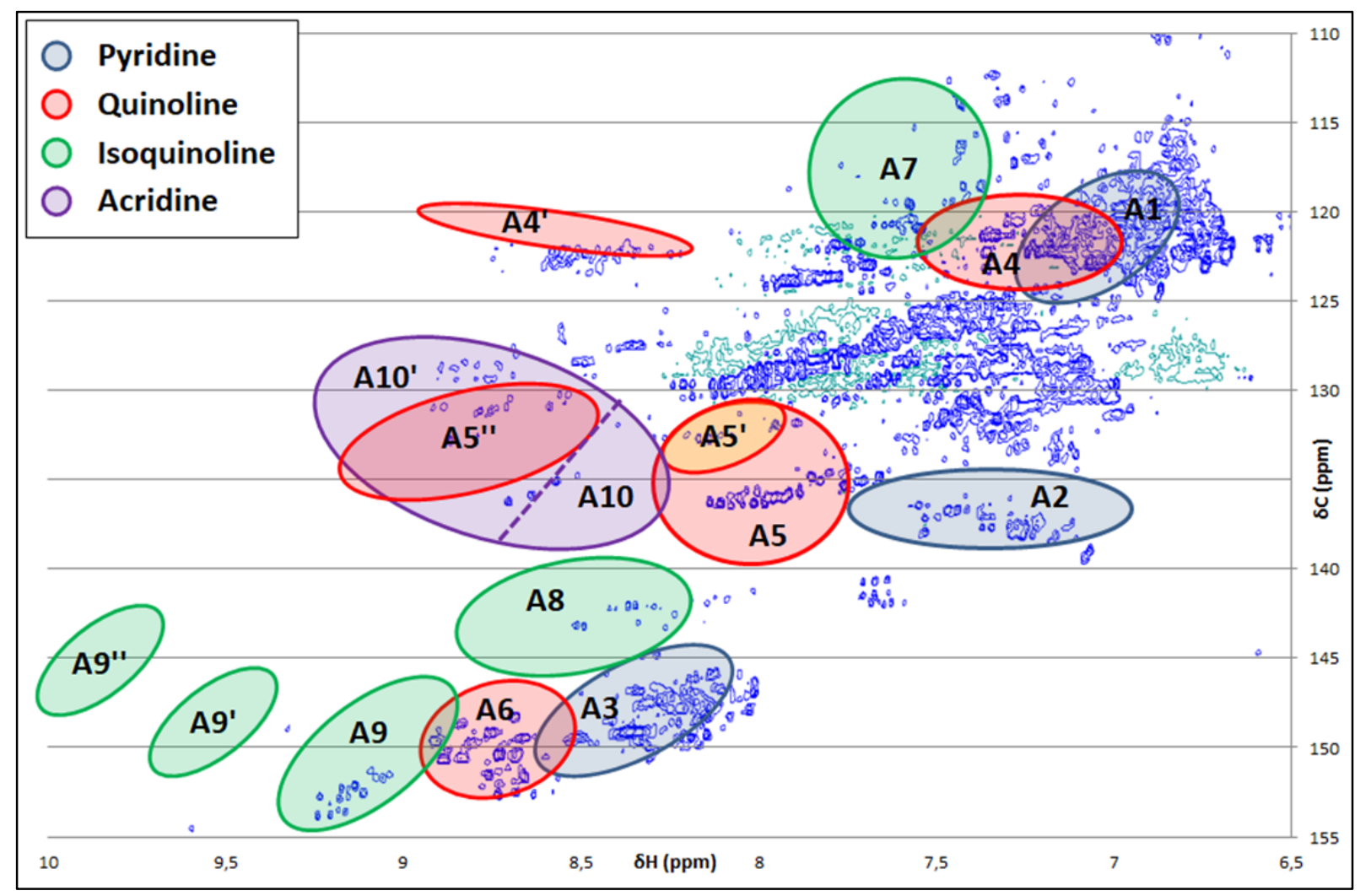

Figure 4. $\left\{{ }^{1} \mathrm{H},{ }^{13} \mathrm{C}\right\}$ HSQC spectra $\left(300 \mathrm{~K}, 300 \mathrm{MHz}, \mathrm{CD}_{2} \mathrm{Cl}_{2}\right)$ of the $\mathrm{GO}$ with areas as defined in Figure 3.

The signal observed under A1, A4 and A7 is diffuse and does not allow, as expected, to distinguish confidently these 3 areas. As expected too, the interference between A5' and A10' makes impossible the assignation of the signals under these areas. Excepted these 5 areas, all others seem to be in accordance with the different groups of signals in the GO spectrum in HSQC. A2 and A3 of pyridine derivatives are faintly shifted from the corresponding signals. It would be necessary to adjust these areas, particularly A3 in order to not incorporate low intensity signals certainly belonging to isoquinoline derivatives and consequently to $\mathrm{A} 8$. A4' is slightly above the expected signal and seems less extensive than predicted. However, these compounds are so specific that a carefull validation is required before validating this area. $\mathrm{C}^{4}-\mathrm{H}^{4}$ correlations 
of quinoline derivatives are divided in two areas A5 and A5'. On the one hand, A5 is distinguishable and as expected, relatively well-separated from A2 and A10. On the other hand, the signals under A5' are less apparent which is certainly due to the fact that benzo(f)quinoline derivatives are specific molecules and present at low concentrations in this GO. For A6, the signal of this zone is framed by A3 and A9 but there is less overlap than predicted especially with A9. The signals corresponding to A9' seem more shielded and expanded than expected and no signal is visible on the spectrum under A9', It may be necessary to accumulate more or to concentrate more the extract to observe these very specific correlations.

The signals corresponding theoriticaly to A8 are most shielded than predicted. Sarma et al. ${ }^{35}$ made NMR spectra of isoquinoline and found at $\delta_{\mathrm{H}}$ of $8.52 \mathrm{ppm}$ in the $\mathrm{CDCl}_{3}$ for the proton in position 3 instead of $8.8 \mathrm{ppm}$ by PS-ACDL. This confirms the shift between the prediction and the signal obtained.

Overall, most of simulated areas match with groups of signals observed in the basic nitrogen fraction of the GO. However, certain areas seem slightly shifted from the corresponding signal. To confirm most of correlations, a few mg of pyridine, quinoline, isoquinoline and acridine were added to the GO extract. The spectrum obtained by HSQC is reported in the Figure 5. 


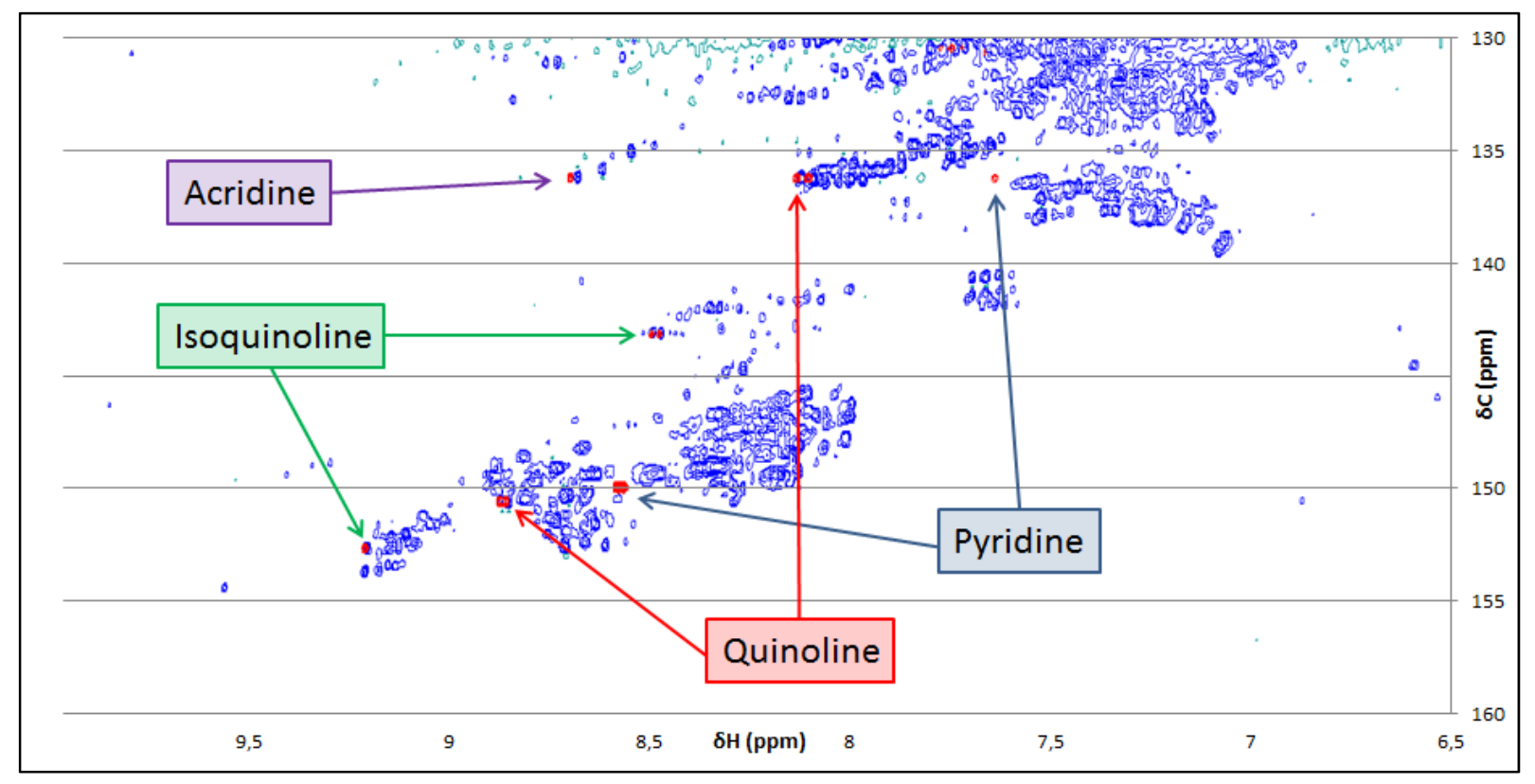

Figure 5. $\left\{{ }^{1} \mathrm{H},{ }^{13} \mathrm{C}\right\}$ HSQC spectra $\left(300 \mathrm{~K}, 300 \mathrm{MHz}, \mathrm{CD}_{2} \mathrm{Cl}_{2}\right)$ of the $\mathrm{GO}$ (blue spectrum) and the GO doped with pyridine, quinoline, isoquinoline and acridine (red spectrum).

As demonstrated previously, each head of family indicates the left limit of the areas and confirms the correlations. Especially, the position of isoquinoline signals corroborates with the data of Sarna et al. and confirms that A8 is located in a more shielded zone in ${ }^{1} \mathrm{H}$ NMR. Even if PS-ACDL predicts areas of interest with $\mathrm{CDCl}_{3}$ as solvent, it is possible to distinguish and confirm most of these areas on HSQC spectrum of a $\mathrm{GO}$ in $\mathrm{CD}_{2} \mathrm{Cl}_{2}$. These results confirm the interest of HSQC to enhance identification of basic N-compounds in GO. According to their localization, HSQC signals of basic nitrogen compounds give specific information about the alkylation on the $\mathrm{N}$ ring and also allow to differentiate isoquinoline and quinoline derivatives. Moreover, this can help identify new nitrogen species in middle distillates. For example, the well-disctinct signals observed at $\delta_{\mathrm{H}} / \delta_{\mathrm{C}}$ of $7.65 / 141.3 \mathrm{ppm}$ cannot be assigned to "classical basic nitrogen compounds" and the identification of this new family is still in progress. 


\section{CONCLUSION}

A mapping of the correlations $\delta_{\mathrm{H}} / \delta_{\mathrm{C}}$ at a specific position of the aromatic ring containing nitrogen was carried out with PS-ACDL on pyridine, quinoline, isoquinoline and acridine derivatives. After correction of few chemical shifts outliers with data from literature, it was possible to identify sixteen areas of interest. Even if PS-ACDL predicts areas of interest with $\mathrm{CDCl}_{3}$ as solvent, it is possible to distinguish and confirm most of these areas on HSQC spectrum of a $\mathrm{GO}$ in $\mathrm{CD}_{2} \mathrm{Cl}_{2}$ by doping with pur compounds.

Consequently, a new methodology is available. It consists in extracting the basic compounds of middle distillate cuts by flash chromatography and analyzing the extracts by ${ }^{1} \mathrm{H}^{13}{ }^{13} \mathrm{C}$ HQC. The methodology allows to provide new fingerprint of structures of basic nitrogen species present in middle distillate cuts. This methodology was applied on a coker GO and achieves to demonstrate the presence of isoquinoline derivatives (not identifiable by GCXGC-NCD). Moreover, it gives very specific details on the close environment of nitrogen atom of basic Ncompounds from GO. This methodology could be further expanded to heavier cuts like vacuum gas oils but work is in progress to firstly validate the quantitative aspect of the approach and maybe find new descriptors for inhibition or deactivation of hydrotreatment catalysts.

\section{ASSOCIATED CONTENT}

The Supporting Information is available free of charge on the ACS Publications website.

This includes the full list of the nitrogen compounds used for the simulation and the cartographies obtained for each family.

\section{AUTHOR INFORMATION}

Corresponding Author

* E-mail: david.proriol@,ifpen.fr 


\section{ORCID}

D. Proriol: 0000-0003-2880-453X

L. Chahen: 0000-0002-0874-9871

\section{Notes}

The authors declare no competing financial interest.

\section{REFERENCES}

1) Van Looij, F.; Van Der Laan, P.; Stork, W.H.J.; DiCamillo, D.J.; Swain J. Key parameters in deep hydrodesulfurization of diesel fuel. Appl. Catal. A 1998, 170, 1-12

2) Zeuthen, P.; Knudsen, K.G.; Whitehurst, D.D. Organic nitrogen compounds in gas oil blends, their hydrotreated products and the importance to hydrotreatment. Catal. Today 2001, 65, $307-314$

3) Laredo, G.C.; De los Reyes, J.A.; Cano, J.L.; Castillo, J.J.; Altamirano, E. Inhibition effects of nitrogen compounds on the hydrodesulfurization of dibenzothiophene. Appl Catal A 2001, 207, 103-112

4) Rana, M.S.; Al-Barood, A.; Brouresli, R.; Al-Hendi, A.W.; Mustafa, N. Effect of organic nitrogen compounds on deep hydrodesulfurization of middle distillate. Fuel Process. Technol. 2018, 177, 170-178

5) Prado, G.H.C.; Rao, Y.; de Klerk, A. Nitrogen Removal from Oil: A Review. Energy Fuels 2017, 31, 14-36

6) Da Silva, J.M.; Machado, M.E.; Maciel, G.P.S.; Dal Molin, D.; Caramão, E.B. Speciation of nitrogen-containing compounds in an unfractionated coal tar sample by comprehensive two- 
dimensional gas chromatography coupled to time-of-flight mass spectrometry. J. Chromatogr. A 2014, 1373, 159-168

7) Salazar, N.; Schmidt, S. B.; Lauritsen, J. V. Adsorption of nitrogenous inhibitor molecules on $\mathrm{MoS} 2$ and CoMoS hydrodesulfurization catalysts particles investigated by scanning tunneling microscopy. J. Catal. 2019, 370, 232-240

8) Vít, Z; Kaluža, L.; Gulková, D. Comparison of nitrogen tolerance of PdMo/A12O3 and $\mathrm{CoMo} / \mathrm{A} 12 \mathrm{O} 3$ catalysts in hydrodesulfurization of model compounds. Fuel 2014, 120, 86-90

9) Machado, M. E. Comprehensive two-dimensional gas chromatography for the analysis of nitrogen-containing compounds in fossil fuels: A review. Talanta 2019, 198, 263-276

10) Von Mühlen, C.; De Oliveira, E.C.; Morrison, P.D.; Zini, C.A.; Caramão, E.B.; Marriott, P.J. Qualitative and quantitative study of nitrogencontaining compounds in heavy gas oil using comprehensive two-dimensional gas chromatography with nitrogen phosphorus detection. J. Sep. Sci. 2007, 30, 3223-3232

11) Wiwel, P.; Knudsen, K.; Zeuthen, P.; Whitehurst, D. Assessing Compositional Changes of Nitrogen Compounds during Hydrotreating of Typical Diesel Range Gas Oils Using a Novel Preconcentration Technique Coupled with Gas Chromatography and Atomic Emission Detection. Ind. Eng. Chem. Res. 2000, 39, 533-540

12) Mushrush, G.W.; Beal, E.J.; Hardy, D.R.; Hughes, J.M. Nitrogen compound distribution in middle distillate fuels derived from petroleum, oil shale, and tar sand sources. Fuel Process. Technol. 1999, 61, 197-210 
13) Cheng, X.; Zhao, T.; Fu, X.; Hu, Z. Identification of nitrogen compounds in RFCC diesel oil by mass spectrometry. Fuel Process. Technol. 2004, 85, 1463-1472

14) Adam, F.; Bertoncini, F.; Brodusch, N.; Durand, E.; Thiébaut, D.; Espinat, D.; Hennion, M.-C. New benchmark for basic and neutral nitrogen compounds speciation in middle distillates using comprehensive two-dimensional gas chromatography. J. Chromatogr. A 2007, 1148, 5564

15) Dutrieza, T.; Borrasa, J.; Courtiadea, M.; Thiébautb, D.; Dulota, H.; Bertoncinia, F.; Hennion, M.-C. Challenge in the speciation of nitrogen-containing compounds in heavy petroleum fractions by high temperature comprehensive two-dimensional gas chromatography. $J$. Chromatogr. A 2011, 1218, 3190-3199

16) Wiwel, P.; Hinnemann, B.; Hidalgo-Vivas, A.; Zeuthen, P.; BPetersen, .O.; Duus J.Ø. Characterization and Identification of the most Refractory Nitrogen Compounds in Hydroprocessed Vacuum Gas Oil. Ind. Eng. Chem. Res. 2010, 49, 3184-3193

17) Lissitsyna, K.; Huertas, S.; Quintero, L.C.; Polo, L.M. Novel simple method for quantitation of nitrogen compounds in middle distillates using solid phase extraction and comprehensive two-dimensional gas chromatography. Fuel 2013, 104, 752-757

18) Chahen, L.; Quoineaud, A.-A.; Proriol, D.; Artero, S.; Vidalie, M.; Neyret-Martinez F.; Rivallan M. Speciation of Basic Nitrogen Compounds in Gas Oils and Vacuum Gas Oils by Derivatization with BF3 prior to NMR Analysis. Energy Fuels 2017, 31, 10752-10759

19) ACD/Labs, version 2017.1.2;ACD Labs, Toronto, ON, Canada 20) https://sdbs.db.aist.go.jp/sdbs/cgi-bin/cre index.cgi. Accessed 2019 
21) Bergmann, A.M.; Oldham, A.M.; You W.; Brown, M.K. Copper-catalyzed cross-coupling of aryl-, primary alkyl-, and secondary alkylboranes with heteroaryl bromides. Chem. Commun. 2018, 54, 5381-5384

22) Sanderson, J.N.; Dominey, A.P.; Percy, J.M. Iron-Catalyzed Isopropylation of ElectronDeficient Aryl and Heteroaryl Chlorides. Adv. Synth. Catal. 2017, 359,1007-1017

23) Liu, T.; Zeng, Y.; Zhang, H.; Wei, T.; Wu, X.; Li, N. Facile Pd-catalyzed chemoselective transfer hydrogenation of olefins using formic acid in water. Tetrahedron Lett. 2016, 57, 48454849

24) Pretch, E.; Clerc, T.; Seibl, J.; Simon, W. 1H-NMR. In Table of Spectral Data for Structure Determination of Organic Compounds, $2^{\text {nd }}$ ed.; Fresenius, W., Huber, J.F.K., Pungor, E., Rechnitz, G.A., Simon, W., West, Th.S., Eds.; Springer-Verlag: Berlin Heidelberg New York, 1989; pp H315

25) Li, J.; Zhang, J.; Yang, H.; Jiang, G. Assembly of Diversely Substituted Quinolines via Aerobic Oxidative Aromatization from Simple Alcohols and Anilines. J. Org. Chem. 2017, 82, $3284-3290$

26) Claret, P.A.; Osborne, A.G. NMR spectral studies of quinoline derivatives. Long range 13C-1H coupling constants in methylquinoline derivatives. Org. Magn. Reson. 1976, 8, 147-150

27) Yi, X.; Xi, C. Copper-Promoted Tandem Reaction of Azobenzenes with Allyl Bromides via $\mathrm{N}=\mathrm{N}$ Bond Cleavage for the Regioselective Synthesis of Quinolines. Org.Lett. 2015, 17, $5836-5839$ 
28) Rousseaux, S.; Liégault, B.; Fagnou, K. Palladium(0)-catalyzed cyclopropane C-H bond functionalization: synthesis of quinoline and tetrahydroquinoline derivatives. Chem. Sci. 2012, 3, $244-248$

29) Wei, W.-T.; Cheng, Y.-J.; Hu, Y.; Chen, Y.-Y.; Zhang, X-J.; Zou, Y.; Yan, M. Concise Synthesis of 4-Arylquinolines via Intramolecular Cyclization of Allylamines and Ketones. Adv. Synth. Catal. 2015, 357, 3474-3478

30) Stephens, D.E.; Lakey-Beitia, J.; Burch, J.E.; Arman, H.D.; Larionov, O.V. Mechanistic insights into the potassium tert-butoxide-mediated synthesis of N-heterobiaryls. Chem. Commun. 2016, 52, 9945-9948

31) Edison, A.S.; Schroeder, F.C. Modern Methods in Natural Products Chemistry, Comprehensive Natural Products. In Comprehensive Natural Products II, $1^{\text {st }}$ ed.; Liu, H.-W., Mander, L., Eds.; Elsevier: Amsterdam, 2010; Vol. 9, pp 169-196

32) Koskela, H.; Heikkilä, O.; Kilpeläinen, I.; Heikkinen, S. Quantitative two-dimensional HSQC experiment for high magnetic field NMR spectrometers. J. Magn. Reson. 2010, 202, 2433

33) Farjon, J.; Milande, C.; Martineau, E.; Akoka, S.; Giraudeau P. The FAQUIRE Approach: FAst, QUantitative, hIghly Resolved and sEnsitivity Enhanced 1H, 13C Data. Anal. Chem. 2018, $90,1845-1851$

34) Schleucher, J.; Schwendinger, M.; Sattler, M.; Schmidt, P.; Schedletzky, O.; Glaser, S.J.; Sorensen, O.W.; Griesinger, C. A general enhancement scheme in heteronuclear multidimensional NMR employing pulsed field gradients. J. Biomol. NMR 1994, 4, 301-306 
35) Sarma, D.; Majumdar, B.; Sarma, T.K. Carboxyl-Functionalized Carbon Dots as Competent Visible Light Photocatalysts for Aerobic Oxygenation of Alkyl Benzenes: Role of Surface Functionality. ACS Sustainable Chem. Eng. 2018, 6, 16573-16585 